\title{
Cocaine-Induced Acute Myocardial Infarction
}

\author{
Shereif H. Rezkalla, MD and Robert A. Kloner, MD, PhD
}

\begin{abstract}
Acute myocardial infarction may occur following cocaine use. Cocaine-induced infarction is particularly common in younger patients aged 18 to 45 years old. Patients may or may not have angiographic evidence of coronary artery disease at the time of their acute event. Previous studies have shown that coronary artery spasm occurs with cocaine use, and perhaps platelet activation, both contributing to a process that may culminate in coronary artery occlusion. Primary coronary intervention should be the preferred revascularization modality by an experienced team. Thrombolytic therapy needs to be instituted if this intervention is unavailable. Beta blockers should be utilized with caution since they may increase coronary spasm or cause a paradoxical rise in blood pressure. They should be avoided in the early hours of the infarction, but be instituted prior to patient discharge. Interruption of cocaine abuse is the cornerstone of secondary prevention in cocaine-related myocardial infarction.
\end{abstract}

Keywords: Acute myocardial infarction; Cocaine; Heart disease; Coronary artery disease;

Coronary spasm; Platelet aggregation; Platelet function; Thrombosis

$\mathrm{M}$ demonstrated that cocaine administered to laboratory animals resulted in atrial and ventricular arrhythmias, myocardial ischemia with coronary vasoconstriction, as well as a direct depression in myocyte function. ${ }^{1,2}$ Would similar effects occur in humans? In the mid-1980s, Isner et $\mathrm{al}^{3}$ reported high grade ventricular arrhythmias, myocardial infarction, even sudden death was temporarily related to cocaine use. A striking observation in Isner's work was that cocaine use did not need to be chronic in order to precipitate a cardiac event. In some cases, recreational use was associated with myocardial infarction. Myocardial infarction was described as both transmural or non-Q wave infarction. ${ }^{4}$ Years later, it became well established that adverse cardiac effects of cocaine use are a tragic reality. ${ }^{5,6}$ More disturbing is the occurrence of adverse cardiac events even when cocaine is used in medicine, i.e., when intranasal and intratracheal applications are utilized as a local anesthetic. ${ }^{7-9}$ A survey conducted 3 years ago revealed that approximately $50 \%$ of otolaryngologists still use the solution of cocaine as a local anesthetic. ${ }^{10}$ This report will focus on the development of myocardial infarction in cocaine users. It is important for the reader to appreciate that the use of cocaine also has been associated with other cardiac-related disorders, such as cardiomyopathy, hypertension, aortic aneurysm and non-cardiac chest pain.

\section{Incidence}

Establishing the incidence of myocardial infarction associated with cocaine use is clearly a very difficult task; however, in selected case reports, it appeared to be relatively high. ${ }^{11}$ Mittleman et $\mathrm{al}^{12}$ reported a rate of $1 \%$ in a retrospective study of 3,946 patients presenting with acute myocardial infarction. The study suggested that the incidence of occurrence was highest during the first hour after administration and fell quickly in subsequent hours. Others have shown a much higher incidence which is apparently dependent on the city where a particular study is conducted and the socioeconomic status of the cohort. The incidence is likely to be underestimated, since the psychological state and euphoria that accompany cocaine use reduce the number of those who seek help, particularly in patients with smaller and/or non-complicated myocardial infarctions. The incidence is much higher $(25 \%)$ in younger patients aged 18 to 45 years old ${ }^{13}$ and particularly in those with other cardiac risk factors. ${ }^{14}$ However, any incidence is clearly unacceptable, since it is a preventable condition. Therefore, 
understanding the possible mechanism(s) of cocaine-induced myocardial infarction is crucial in determining the best management strategy of such patients.

\section{Physiology}

The pathophysiology of myocardial infarction is usually associated with a progression of atherosclerotic coronary artery disease, with or without plaque rupture. Animal studies have shown that cocaine administration is associated with more extensive atherosclerotic changes. ${ }^{15}$ Therefore, it was intuitive to consider the possibility that cocaine may accelerate coronary artery disease, since cocaine users who underwent coronary angiography had a $42 \%$ incidence of coronary artery disease. ${ }^{16}$ Many case reports suggested that there is significant progression of coronary artery disease in cocaine users, ${ }^{17,18}$ while others have described coronary aneurysms ${ }^{19}$ or dissections. ${ }^{20}$ Inhibition of the uptake of catecholamines by the cell and the resultant effects, including hypertension, has the potential of accelerating atherosclerosis. Controlled studies, however, are the only way to address this important question. Pletcher et al ${ }^{21}$ examined 3,038 patients in the Coronary Artery Risk Development in Young Adults (CARDIA) study with a multidetector computerized tomography scanner and compared the degree of coronary calcification, which is a surrogate marker for the presence of coronary artery disease in cocaine users and nonusers. Initial analysis showed that cocaine users had more calcification; however, when the data were adjusted for a variety of risk factors, this significance was lost. Thus, while it seems that cocaine users had more extensive coronary artery disease or rapid progression of that disease, it may be due to risk factors in those patients, including concomitant tobacco abuse and hypertension. Furthermore, Kolodgie et $\mathrm{a}^{22}$ reported that despite extensive coronary atherosclerosis, plaque rupture was less common in cocaine-related myocardial infarction. It is likely that factors unique to cocaine use may contribute to the occurrence of infarctions.

Two additional likely mechanisms for cocaine-induced myocardial infarction are coronary artery spasm and platelet activation (figure 1). An early study observed generalized coronary artery vasospasm and a decrease in coronary flow when cocaine was injected intravenously to healthy phenobarbital anesthetized dogs. ${ }^{15}$ The occurrence was consistent in all animals, although the degree of vasospasm varied among dogs. Isolated case reports also suggested vasospasm as a cause for the infarction. ${ }^{23,24}$ Lange et $\mathrm{al}^{25}$ studied 45 patients who underwent coronary angiography for evaluation of chest pain. Coronary sinus blood flow and the diameter of the coronary arteries were measured at baseline, and were also measured after intranasal administration of cocaine or normal saline. Subsequent to administration of the cocaine, there was a decrease in both coronary artery blood flow and epicardial artery diameter, a finding consistent with our animal data. These effects were blocked by phentolamine, an alpha adrenergic blocking agent, suggesting that stimulation of the alpha receptors is the likely mechanism of

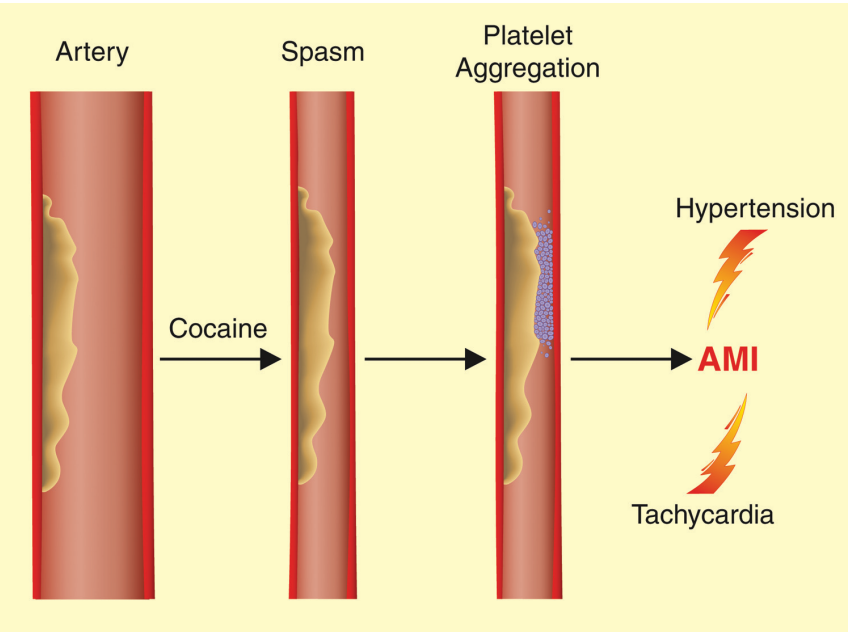

Figure 1. Mechanism of cocaine-induced myocardial infarction. Arteries with or without coronary artery disease will have spasm and increased platelet aggregation. The associated increase in blood pressure and heart rate adds insult to the injury.

these changes. The degree of coronary artery spasm at sites of atherosclerosis is usually more pronounced. ${ }^{26}$ Diseased arterial segments do not have healthy endothelial cells which make it more vulnerable to the effects of cocaine. More disturbing was that the ischemic effect occurred at a time where heart rate and blood pressure increased requiring more, not less, blood supply. The same group utilizing similar methodology showed that this decrease in blood flow occurs in both normal, as well as diseased vascular segments. When smoking was combined with cocaine, the effect in the diseased coronary segments was more obvious. ${ }^{27}$

Cocaine use is also associated with an activation of platelets, leading to increased platelet adhesiveness and aggregation that play a major role in the development of coronary thrombi. Multiple case reports described coronary thrombosis in cocaine users presenting with acute myocardial infarction, occasionally in the presence of normal coronary arteries. ${ }^{28-30}$ Stenberg et $\mathrm{al}^{31}$ described a 38-year-old man with simultaneous thrombosis of both right coronary artery and left descending coronary artery following intravenous cocaine use. These reports led us to study the effects of cocaine on human platelets. ${ }^{32}$ Platelets from human volunteers were incubated with cocaine dissolved in normal saline or normal saline alone for 10 minutes at $37^{\circ} \mathrm{C}$. Cocaine exposure resulted in a significant increase in platelet aggregation induced with adenosine diphosphate. Heesch et $\mathrm{al}^{33}$ reported that cocaine caused platelet activation with release of platelet alpha granules, and the occurrence of microaggregates were observed in a separate in vitro study.

Thus, with acute use of the drug, coronary spasm, decrease in blood flow, as well as activation of platelets may occur which may result in the development of coronary thrombosis and myocardial infarction. At the time of decreased oxygen 
supply to the myocardium, the intense sympathomimetic effects of cocaine results in hypertension and tachycardia. The resulting increase in tissue demands adds an insult to the injury. Zimmerman et al ${ }^{34}$ described a young 29 -year-old man with normal coronary arteries who developed coronary spasm and a coronary thrombus following cocaine use, emphasizing the sequence of events that may culminate in myocardial infarction.

\section{Diagnosis}

Diagnosis of cocaine-induced acute myocardial infarction is made by obtaining a careful history and physical examination of the patient along with appropriate laboratory tests, cardiac enzymes and classic electrocardiographic findings. Cocaineinduced myocardial infarction needs to be suspected in young patients presenting with infarction. Such patients do not voluntarily admit to cocaine use, and therefore direct inquiry about drug use is important. Blood and urine for drug screening may be obtained if there is a high index of suspicion for cocaine use. While cocaine does not last long in the patient's blood, cocaine metabolites such as benzoylecgonine and ecgonine may be detected in the urine for up to 8 days after intake and for a very long time in the patient's hair.

Elevated troponin may be more specific than creatinine kinase in this setting. History taking can be a real challenge with the altered level of consciousness that is observed in many cocaine using patients. ${ }^{35}$ Resting perfusion imaging with technetium-99m Sestamibi may be useful if acquired in a timely manner. ${ }^{36}$ A perfusion image may clarify the clinical picture when atypical symptoms are present or the electrocardiogram is not diagnostic; however, this has not gained a wide clinical application because of the difficulty in obtaining the perfusion image urgently and in the inherent time delay that is involved. The most useful bedside test is the two-dimensional echocardiogram showing a clear regional wall motion abnormality.

While some patients will have a clear diagnosis, others may not. How should emergency departments handle these cases? Weber et $\mathrm{al}^{37}$ prospectively studied 302 patients who presented to the emergency room with cardiac symptoms following cocaine use. Patients who were at mild or moderate risk were observed in the emergency department for 9 to 12 hours. Those who had normal troponin I, serial electrocardiograms with no significant changes, no recurrent cardiac symptoms and no cardiac arrhythmias were discharged. At 30 days, none of the patients died and the risk for recurrent cardiac events was very low. ${ }^{37}$ In the emergency department, those patients with evidence of acute transmural myocardial infarction and at high risk (e.g., elevated cardiac enzymes) need to be admitted for immediate therapy. Those at low to intermediate risk may be observed in the department before a final plan of disposition is made. In a study by Gitter et al ${ }^{38}$ of 101 cocaine patients admitted with chest pain, $18 \%$ of patients simply had pleuritic noncardiac chest pain. While admitting electrocardiograms often showed ST or T wave abnormalities, the abnormalities were nonspecific and were mostly related to hypertensive heart disease or early repolarization.

\section{Management}

If a cocaine user presents with ST elevation myocardial infarction within 6 hours of onset of chest pain, immediate thrombolytic therapy or acute percutaneous coronary intervention needs to be implemented as soon as possible in patients with definite ST elevation myocardial infarction. Acute intervention is always preferred if a qualified interventional team is readily available onsite. Since platelets are an important part of the pathophysiology in coronary thrombosis, IIB/IIIA platelet receptor inhibitors should be an integral part of acute intervention.

When a coronary catheterization laboratory is not immediately available, thrombolytic therapy should be administered intravenously. ${ }^{39,40}$ In a retrospective study of cocaine users, thrombolytic therapy was found to be safe, but patients must meet the accepted inclusion and exclusion criteria before this therapy should be initiated. A word of caution about the use of thrombolytic therapy in this group of patients; cocaine users may have altered consciousness and sustained various injuries that may not be obvious on initial evaluation, and therefore bleeding risk should be carefully considered, particularly cerebral bleed. ${ }^{41-43}$ Aortic dissection has been reported with cocaine use, and in that setting, thrombolytics should be avoided. A careful examination and chest $x$-ray should be obtained prior to initiation of thrombolytic therapy. If there is any neurologic symptom or sign detected, then appropriate imaging may need to be obtained emergently to rule out carotid artery dissection or a cerebral bleed.

Oxygen, aspirin, nitrates and benzodiazepines should be immediately administered. ${ }^{4}$ It is recommended that all patients with myocardial infarction receive beta blocker therapy at presentation, which reduces infarction size, decreases cardiac arrhythmias and improves mortality. In cocaine users, however, blocking beta receptors may leave the alpha effect unopposed, causing paradoxically increased blood pressure which may increase myocardial oxygen demand and infarction size. In addition, unopposed alpha blockade can induce coronary artery vasospasm. Lange et $\mathrm{al}^{45}$ administered propranolol to 30 patients following intranasal cocaine administration. While cocaine administration led to a decrease in coronary artery blood flow, beta blocker administration resulted in a further decrease in flow and an increase in coronary resistance. ${ }^{45}$ Thus, beta blocker use should be avoided in the early phases of treatment while cocaine's effects are still present, but started prior to hospital discharge when cocaine's effects have abated. Counseling patients to avoid cocaine use should be performed routinely.

Cocaine has a potent effect on membrane ion channels, and when this effect is added to tissue ischemia and left 
ventricular dysfunction, it is not surprising that cocaine results in various cardiac arrhythmias. High grade ventricular arrhythmias, including Torsades de pointes, are not uncommon and patients need to be closely monitored and appropriately treated.

\section{Conclusion}

Cocaine use may lead to the development of acute myocardial infarction, but the incidence of infarction is difficult to determine, and varies widely in the literature. Some, but not all, studies suggest that cocaine hastens the development of coronary artery atherosclerosis. However, the most plausible mechanism for the development of myocardial infarction in the cocaine user is coronary artery spasm at a time when oxygen demand is increased due to an increase in heart rate and blood pressure that are accompanied by platelet activation, and together culminate in coronary artery occlusion, particularly if the patient has underlying coronary artery disease (figure 1). Thrombolytic therapy or acute intervention should be initiated promptly after assessing for the risk of bleeding and other major complications, such as aortic dissection, severe hypertension or intracerebral hemorrhage. Acute beta blocker use should be viewed with caution, since it may lead to a decrease in coronary flow and an increase in coronary artery resistance. The most important long-term interventions are to enter the patient into a substance abuse program and to educate the patient about the harmful effects that cocaine has upon the heart.

\section{Acknowledgments}

The authors thank Marshfield Clinic Research Foundation for its support through the assistance of Linda Weis and Alice Stargardt in the preparation of this manuscript.

\section{References}

1. Hale SL, Lehmann MH, Kloner RA. Electrocardiographic abnormalities after acute administration of cocaine in the rat. Am J Cardiol 1989;63:1529-1530.

2. Hale SL, Alker KJ, Rezkalla S, Figures G, Kloner RA. Adverse effects of cocaine on cardiovascular dynamics, myocardial blood flow, and coronary artery diameter in an experimental model. Am Heart J 1989;118:927-933.

3. Isner JM, Estes NA 3rd, Thompson PD, Costanzo-Nordin MR, Subramanian R, Miller G, Katsas G, Sweeney K, Sturner WQ. Acute cardiac events temporally related to cocaine abuse. N Engl J Med 1986;315:1438-1443.

4. Kossowsky WA, Lyon AF, Chou SY. Acute non-Q wave cocainerelated myocardial infarction. Chest 1989;96:617-621.

5. Lange RA, Hillis LD. Cardiovascular complications of cocaine use. N Engl J Med 2001;345:351-358.

6. Kloner RA, Rezkalla SH. Cocaine and the heart. N Engl J Med 2003;348:487-488.

7. Ross GS, Bell J. Myocardial infarction associated with inappropriate use of topical cocaine as treatment for epistaxis. Am J Emerg Med 1992;10:219-222.

8. Osula S, Stockton P, Abdelaziz MM, Walshaw MJ. Intratracheal cocaine induced myocardial infarction: an unusual complication of fibreoptic bronchoscopy. Thorax 2003;58:733-734.

9. Makaryus JN, Makaryus AN, Johnson M. Acute myocardial infarction following the use of intranasal anesthetic cocaine. South Med J 2006;99:759-761
10. Long H, Greller H, Mercurio-Zappala M, Nelson LS, Hoffman RS. Medicinal use of cocaine: a shifting paradigm over 25 years. Laryngoscope 2004;114:1625-1629.

11. Smith HW 3rd, Liberman HA, Brody SL, Battey LL, Donohue $\mathrm{BC}$, Morris DC. Acute myocardial infarction temporally related to cocaine use. Clinical, angiographic, and pathophysiologic observations. Ann Intern Med 1987; 107:13-18

12. Mittleman MA, Mintzer D, Maclure M, Tofler GH, Sherwood JB, Muller JE. Triggering of myocardial infarction by cocaine. Circulation 1999;99:2737-2741.

13. Qureshi AI, Suri MF, Guterman LR, Hopkins LN. Cocaine use and the likelihood of nonfatal myocardial infarction and stroke: data from the Third National Health and Nutrition Examination Survey. Circulation 2001;103:502-506.

14. Hollander JE, Shih RD, Hoffman RS, Harchelroad FP, Phillips $\mathrm{S}$, Brent J, Kulig K, Thode HC Jr. Predictors of coronary artery disease in patients with cocaine-associated myocardial infarction. Cocaine-Associated Myocardial Infarction (CAMI) Study Group. Am J Med 1997;102:158-163.

15. Kloner RA, Hale S, Alker K, Rezkalla S. The effects of acute and chronic cocaine use on the heart. Circulation 1992;85:407-419

16. Rezkalla SH, Hale S, Kloner RA. Cocaine-induced heart diseases. Am Heart J 1990;120:1403-1408.

17. Wilson LD. Rapid progression of coronary artery disease in the setting of chronic cocaine abuse. J Emerg Med 1998; 16:631-634.

18. Patrizi R, Pasceri V, Sciahbasi A, Summaria F, Rosano GM, Lioy E. Evidence of cocaine-related coronary atherosclerosis in young patients with myocardial infarction. J Am Coll Cardiol 2006;47:2120-2122.

19. Satran A, Bart BA, Henry CR, Murad MB, Talukdar S, Satran $\mathrm{D}$, Henry TD. Increased prevalence of coronary artery aneurysms among cocaine users. Circulation 2005; 111:2424-2429.

20. Jaffe BD, Broderick TM, Leier CV. Cocaine-induced coronaryartery dissection. N Engl J Med 1994;330:510-511.

21. Pletcher MJ, Kiefe CI, Sidney S, Carr JJ, Lewis CE, Hulley SB. Cocaine and coronary calcification in young adults: the Coronary Artery Risk Development in Young Adults (CARDIA) Study. Am Heart J 2005;150:921-926.

22. Kolodgie FD, Virmani R, Cornhill JF, Herderick EE, Smialek J. Increase in atherosclerosis and adventitial mast cells in cocaine abusers: an alternative mechanism of cocaineassociated coronary vasospasm and thrombosis. J Am Coll Cardiol 1991;17:1553-1560.

23. Weiss RJ. Recurrent myocardial infarction caused by cocaine abuse. Am Heart J 1986;111:793.

24. Schachne JS, Roberts BH, Thompson PD. Coronary-artery spasm and myocardial infarction associated with cocaine use. N Engl J Med 1984;310:1665-1666.

25. Lange RA, Cigarroa RG, Yancy CW Jr, Willard JE, Popma JJ, Sills MN, McBride W, Kim AS, Hillis LD. Cocaine-induced coronary-artery vasoconstriction. N Engl J Med 1989;321:1557-1562.

26. Flores ED, Lange RA, Cigarroa RG, Hillis LD. Effect of cocaine on coronary artery dimensions in atherosclerotic coronary artery disease: enhanced vasoconstriction at sites of significant stenoses. J Am Coll Cardiol 1990;16:74-79.

27. Moliterno DJ, Willard JE, Lange RA, Negus BH, Boehrer JD, Glamann DB, Landau C, Rossen JD, Winniford MD, Hillis LD. Coronary-artery vasoconstriction induced by cocaine, cigarette smoking, or both. N Engl J Med 1994;330:454-459.

28. Howard RE, Hueter DC, Davis GJ. Acute myocardial infarction following cocaine abuse in a young woman with normal coronary arteries. JAMA 1985;254:95-96. 
29. Hadjimiltiades S, Covalesky V, Manno BV, Haaz WS, Mintz GS. Coronary arteriographic findings in cocaine abuseinduced myocardial infarction. Cathet Cardiovasc Diagn 1988;14:33-36.

30. Williams MJ, Stewart RA. Serial angiography in cocaineinduced myocardial infarction. Chest 1997;111:822-824.

31. Stenberg RG, Winniford MD, Hillis LD, Dowling GP, Buja LM. Simultaneous acute thrombosis of two major coronary arteries following intravenous cocaine use. Arch Pathol Lab Med 1989;113:521-524.

32. Rezkalla SH, Mazza JJ, Kloner RA, Tillema V, Chang SH. Effects of cocaine on human platelets in healthy subjects. Am J Cardiol 1993;72:243-246.

33. Heesch CM, Wilhelm CR, Ristich J, Adnane J, Bontempo FA, Wagner WR. Cocaine activates platelets and increases the formation of circulating platelet containing microaggregates in humans. Heart 2000;83:688-695.

34. Zimmerman FH, Gustafson GM, Kemp HG Jr. Recurrent myocardial infarction associated with cocaine abuse in a young man with normal coronary arteries: evidence for coronary artery spasm culminating in thrombosis. J Am Coll Cardiol 1987;9:964-968.

35. Trabulsy ME. Cocaine washed out syndrome in a patient with acute myocardial infarction. Am J Emerg Med 1995; 13:538-539.

36. Kontos MC, Schmidt KL, Nicholson CS, Ornato JP, Jesse RL, Tatum JL. Myocardial perfusion imaging with technetium$99 \mathrm{~m}$ sestamibi in patients with cocaine-associated chest pain. Ann Emerg Med 1999;33:639-645.

37. Weber JE, Shofer FS, Larkin GL, Kalaria AS, Hollander JE. Validation of a brief observation period for patients with cocaine-associated chest pain. N Engl J Med 2003; 348:510-517.

38. Gitter MJ, Goldsmith SR, Dunbar DN, Sharkey SW. Cocaine and chest pain: clinical features and outcome of patients hospitalized to rule out myocardial infarction. Ann Intern Med 1991;115:277-282.

39. Yao SS, Spindola-Franco H, Menegus M, Greenberg M, Goldberger M, Shirani J. Successful intracoronary thrombolysis in cocaine-associated acute myocardial infarction. Cathet Cardiovasc Diagn 1997;42:294-297.

40. Rod JL, Zucker RP. Acute myocardial infarction shortly after cocaine inhalation. Am J Cardiol 1987;59:161.

41. Hollander JE, Burstein JL, Hoffman RS, Shih RD, Wilson LD. Cocaine-associated myocardial infarction. Clinical safety of thrombolytic therapy. Cocaine Associated Myocardial Infarction (CAMI) Study Group. Chest 1995;107:1237-1241.

42. Bush HS. Cocaine-associated myocardial infarction. A word of caution about thrombolytic therapy. Chest 1988;94:878.

43. Hoffman RS, Hollander JE. Thrombolytic therapy and cocaineinduced myocardial infarction. Am J Emerg Med 1996; 14:693-695.

44. American Heart Association. 2005 American Heart Association guidelines for cardiopulmonary resuscitation (CPR) and emergency cardiovascular care (EC) of pediatric and neonatal patients: pediatric advanced life support. Pediatrics 2006;117:e1005-e1028. doi:10.1542/peds.2006-0346.

45. Lange RA, Cigarroa RG, Flores ED, McBride W, Kim AS, Wells PJ, Bedotto JB, Danziger RS, Hillis LD. Potentiation of cocaine-induced coronary vasoconstriction by betaadrenergic blockade. Ann Intern Med 1990;112:897-903.

\section{Author Affiliations}

Shereif H. Rezkalla, MD

Department of Cardiology

Marshfield Clinic

1000 North Oak Avenue

Marshfield, Wisconsin

Robert A. Kloner, MD, PhD

The Heart Institute, Good Samaritan Hospital,

Division of Cardiovascular Medicine,

Keck School of Medicine,

University of Southern California,

Los Angeles, California 